\title{
Quality of Life Following Stereotactic Body Radiotherapy Versus Three-Dimensional Conformal Radiotherapy for Vertebral Metastases: Secondary Analysis of an Exploratory Phase II Randomized Trial
}

\author{
TANJA SPRAVE ${ }^{1,2}$, VIVEK VERMA ${ }^{3}$, ROBERT FÖRSTER ${ }^{1,2,4}$, INGMAR SCHLAMPP ${ }^{1,2}$, \\ THOMAS BRUCKNER ${ }^{5}$, TILMAN BOSTEL ${ }^{1}$, RAMI ATEAYH EL SHAFIE ${ }^{1}$, \\ NILS HENRIK NICOLAY ${ }^{1,2,6}$, JÜRGEN DEBUS ${ }^{1,2}$ and HARALD RIEF ${ }^{1,2}$ \\ ${ }^{1}$ Department of Radiation Oncology, University Hospital of Heidelberg, Heidelberg, Germany; \\ ${ }^{2}$ Heidelberg Institute of Radiation Oncology (HIRO), Heidelberg, Germany; \\ ${ }^{3}$ Department of Radiation Oncology, Allegheny General Hospital, Pittsburgh, PA, U.S.A.; \\ ${ }^{4}$ Department of Radiation Oncology, University Hospital Zurich, Zurich, Switzerland; \\ ${ }^{5}$ Department of Medical Biometry, University Hospital of Heidelberg, Heidelberg, Germany; \\ ${ }^{6}$ Department of Radiation Oncology, University Hospital of Freiburg, Freiburg, Germany
}

\begin{abstract}
Background/Aim: This was a prespecified secondary analysis of a randomized trial, which analyzed quality of life (QOL), fatigue, and emotional distress following stereotactic body radiotherapy (SBRT) versus conventional three-dimensional conformal radiotherapy (3DCRT) as part of palliative management of painful spinal metastases. Materials and Methods: Fifty-five patients were enrolled in this single-institutional randomized exploratory phase II trial (NCT02358720). Participants were randomly assigned to receive SBRT (single-fraction $24 \mathrm{~Gy}$ ) or $3 D C R T$ (30 Gy/10 fractions). QOL (EORTC QLQ-BM22), fatigue (EORTC QLQ FA13), and emotional distress (QSC-R10) at the end of radiotherapy, along with 3- and 6-month followup were assessed. Results: At all recorded time points, there were no significant $Q O L$ differences between cohorts, including painful sites, pain characteristics, functional impairment, or psychosocial aspects ( $p>0.05$ for all). There were also no differences in all dimensions of fatigue between groups at each recorded time point ( $p>0.05$ for all). Emotional distress was also similar at three $(p=0.248)$ and six months ( $p=0.603)$. Conclusion: Although these results
\end{abstract}

Correspondence to: Tanja Sprave, MD MBA, University of Heidelberg, Department of Radiation Oncology, Im Neuenheimer Feld 400, 69120 Heidelberg, Germany. Tel: +49 6221568202, Fax: +49 6221565353, e-mail: tanja.sprave@ @med.uni-heidelberg.de

Key Words: Spine metastases, stereotactic body radiation therapy, quality of life, fatigue, palliative radiotherapy. demonstrate that SBRT does not cause worse $Q O L$ deteriorations compared to 3DCRT, larger randomized investigations are recommended to corroborate these findings.

Spinal metastases occur in up to $40 \%$ of patients with advanced cancer (1). These can be associated with profound pain, immobility, pathological fractures, and neurological deficits. All of these may considerably reduce quality of life in these patients. Conventionally, fractionated threedimensional conformal radiotherapy (3DCRT) is the standard treatment for painful osseous metastases $(2,3)$. However, spinal stereotactic body radiotherapy (SBRT) is a promising alternative due to the delivery of high, ablative doses for durable local control while controlling doses to adjacent organs-at-risk (OARs) (4-10).

Spinal SBRT has largely been primarily utilized for oligometastatic osseous disease and re-irradiation of osseous metastases (11). Prospective trials using SBRT for bone metastases have reported high tumor control, satisfactory pain response, and low toxicities $(12,13)$.

However, quality of life (QOL) with spinal SBRT has been greatly underexamined, and to date has not been evaluated prospectively. This is important to perform, as QOL is becoming increasingly important to appraise the value of a particular intervention (14-16). This report is a prespecified secondary analysis of a randomized trial, which evaluated quality of life, fatigue, and emotional distress following SBRT versus conventional 3DCRT as part of the palliative management of painful spinal metastases. 


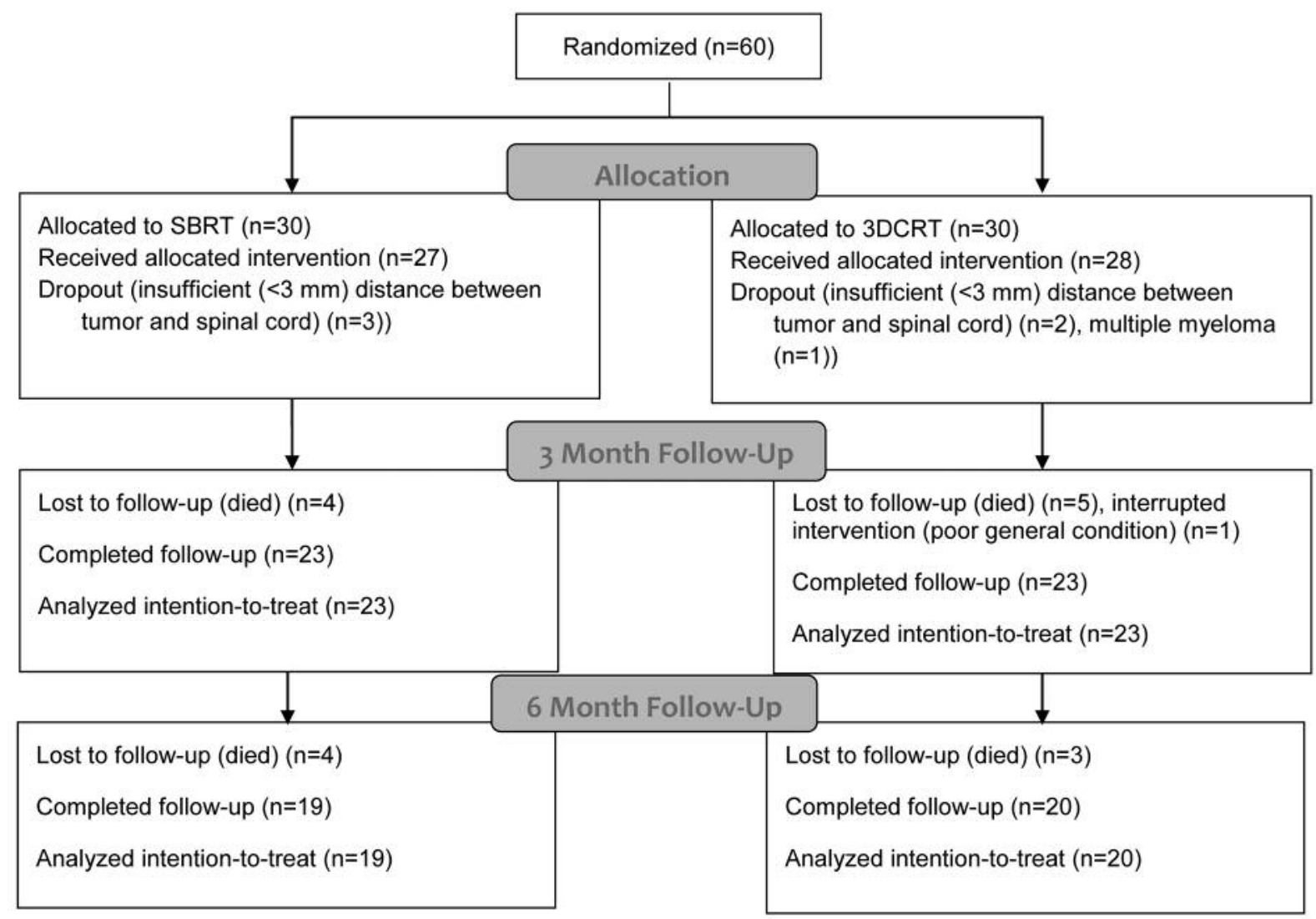

Figure 1. CONSORT diagram of the trial.

\section{Materials and Methods}

Subjects, recruitment strategy, and eligibility for enrollment. The randomized trial, registered on clinicaltrials.gov (NCT02358720), was approved by the Heidelberg University Independent Ethics Committee (Nr. S-431/2013). Additionally, approval was given from the German Federal Office of Radiation Protection (BfS).

From November 2014 to March 2017, 60 patients with histologically confirmed cancer and painful spinal metastases were randomized to high-dose single-fraction SBRT (24 Gy) versus standard fractioned 3DCRT (30 Gy in 10 fractions).

Inclusion criteria were ages 18-80, a Karnofsky performance score $(17 \geq 70$, ability to provide written informed consent, maximum of two irradiated vertebral bodies per region, a maximum of two different vertebral regions affected, and tumor distance $>3 \mathrm{~mm}$ to the spinal cord. Exclusion criteria were subjects with significant neuropsychiatric disorders precluding informed consent, previous RT to the given irradiation site, contraindications for MRI, multiple myeloma or lymphoma histology, or involvement of the cervical spine.

In total, five patients were excluded. Four patients in the SBRT arm had an insufficient distance between tumor and the spinal cord. One participant from the control arm was excluded because of the confirmed diagnosis of multiple myeloma after randomization.
Overall, 55 patients met the inclusion/exclusion criteria and were enrolled into the trial (Figure 1).

Design, randomized allocation, and procedures. Details of the study design have been previously published (18). The primary endpoint of this randomized, single-institutional, exploratory trial was pain response following high-dose single-fraction SBRT versus conventional 3DCRT in patients with painful, previously untreated spinal metastases. The present study was a prespecified secondary analysis of quality of life (QOL) using the EORTC QLQ-BM 22 questionnaire, fatigue using EORTC QLQ-FA 13, and emotional distress according to the FBK 10 questionnaire. These were administered at the end of radiation, and at 3 and 6 months following radiation treatment.

A block randomization approach (block size of 6) was used to ensure that the two groups were balanced. Two different techniques were evaluated on a 1:1 basis according to the randomization list: high-dose, single-fraction ( 24 Gy to the $80 \%$ isodose line) SBRT versus $30 \mathrm{~Gy}$ in 10 fractions of conventional radiotherapy.

Assessment of the secondary endpoints. The prespecified secondary endpoint was QOL, assessed using the EORTC QLQ BM22 questionnaire, which is specially designed for patients with bone metastases. The QLQ BM22 module (range $=0-100$ ) comprises 22 
Table I.

\begin{tabular}{|c|c|c|c|c|c|}
\hline & \multicolumn{2}{|c|}{ SBRT group $n=27$} & \multicolumn{2}{|c|}{3 DCRT group $n=28$} & \multirow[t]{2}{*}{$p$-Value } \\
\hline & $\mathrm{n}$ & $\%$ & $\mathrm{n}$ & $\%$ & \\
\hline \multicolumn{6}{|l|}{ Age (years) } \\
\hline Mean (SD) & $61(8.2)$ & & $63.9(10.8)$ & & 0.225 \\
\hline \multicolumn{6}{|l|}{ Gender } \\
\hline Male & 15 & 55.6 & 13 & 46.4 & 0.499 \\
\hline Female & 12 & 44.4 & 15 & 53.6 & \\
\hline Weight (kg. SD) & $76(19.2)$ & & $78.2(16.4)$ & & \\
\hline Height (cm. SD) & $171.1(8.5)$ & & $172.3(8.7)$ & & \\
\hline \multicolumn{6}{|l|}{ Body mass index (BMI) } \\
\hline Mean (SD) & $25.8(5.8)$ & & $26.5(5.7)$ & & 0.899 \\
\hline \multicolumn{6}{|l|}{ Primary site } \\
\hline Lung cancer & 9 & 33.3 & 10 & 35.7 & \\
\hline Breast cancer & 7 & 26.3 & 10 & 35.7 & \\
\hline Renal cancer & 2 & 7.4 & 2 & 7.1 & \\
\hline Other & 9 & 33.3 & 6 & 21.4 & \\
\hline Localization of metastases & & & & & 0.317 \\
\hline Thoracic & 14 & 51.9 & 19 & 67.9 & \\
\hline Lumbar & 13 & 48.1 & 8 & 28.6 & \\
\hline Number metastases & & & & & 0.301 \\
\hline 1 metastasis & 24 & 88.9 & 22 & 78.6 & \\
\hline 2 metastases & 3 & 11.1 & 6 & 21.4 & \\
\hline \multicolumn{6}{|l|}{ Distant metastases at baseline } \\
\hline Viszeral & 12 & 44.4 & 14 & 51.9 & 0.586 \\
\hline Lung & 11 & 40.7 & 4 & 14.8 & 0.033 \\
\hline Brain & 7 & 25.9 & 3 & 11.1 & 0.161 \\
\hline Tissue & 5 & 18.5 & 4 & 14.8 & 0.715 \\
\hline Hormonetherapy & 6 & 22.2 & 8 & 28.6 & 0.589 \\
\hline Immunotherapy & 8 & 29.6 & 8 & 28.6 & 0.931 \\
\hline Chemotherapy & 11 & 40.7 & 13 & 46.4 & 0.671 \\
\hline Surgery & 8 & 29.6 & 10 & 35.7 & 0.631 \\
\hline Neurological deficit at baseline & 0 & 0 & 1 & 3.6 & 0.322 \\
\hline Bisphosphonate at baseline & 11 & 40.7 & 13 & 46.4 & 0.671 \\
\hline Orthopedic corset at baseline & 3 & 11.1 & 6 & 21.4 & 0.301 \\
\hline \multicolumn{6}{|l|}{ Medication at baseline } \\
\hline Sleeping medication & 1 & 3.7 & 1 & 3.6 & 0.979 \\
\hline Psychiatric medication & 3 & 11.1 & 5 & 17.9 & 0.478 \\
\hline Opiate & 11 & 40.7 & 10 & 35.7 & 0.701 \\
\hline NSAID & 15 & 55.6 & 15 & 53.6 & 0.883 \\
\hline
\end{tabular}

SBRT: Stereotactic body radiotherapy; SD: standard deviation; CUP: cancer of unknown primary; 3DCRT: 3D conformal radiotherapy; NSAID: nonsteroidal inflammatory drug.

items and four scales for the measurement of pain in various parts of the body (painful sites), pain characteristics (persistent pain, recurrent pain), functional impairment (occurrence of pain when performing different activities, interference with everyday activities), and psychosocial aspects (family, worries, hope) (19). Other secondary endpoints were fatigue, and emotional distress. Fatigue was assessed using the EORTC QLQ FA13 (range=0-100) module. This includes 13 items and five scales for measuring cancer-related fatigue (20), with subscales covering physical fatigue, emotional fatigue, cognitive fatigue, interference with daily life, and social sequelae. Emotional distress was assessed using the QSC-R10 (range $=0-50$ ) questionnaire (21). This module is a valid and reliable questionnaire for determining emotional distress and anxiety in cancer patients (22). The questionnaires were filled out by the patients at the study site. All patient records were collected by the authors, and the evaluation included all recorded data up to the 6month follow-up interval.

Radiotherapy. CT simulation was carried out with custom immobilization using Aquaplast ${ }^{\circledR}$ head masks, vacuum mattresses, and/or Wingstep ${ }^{\circledR}$ arm abduction framework. OARs (including the spinal cord) and the clinical target volume (CTV) were delineated on the planning CT with MRI co-registration. The planning target volume (PTV) was to be covered by the $80 \%$ isodose line, and 24 Gy in a 
Table II. Effects of radiotherapy on QOL in both groups (EORTC QLQ BM 22). Treatment effect and Cohen's effect size after 3 and 6 months.

Symptom scales

\begin{tabular}{|c|c|c|c|c|c|c|}
\hline \multirow[b]{2}{*}{ Painful sites } & \multicolumn{3}{|c|}{ SBRT group } & \multicolumn{3}{|c|}{ 3DCRT group } \\
\hline & $\mathrm{n}$ & Mean & $\mathrm{SD}$ & $\mathrm{n}$ & Mean & $\mathrm{SD}$ \\
\hline End of radiotherapy (t1) & 27 & 31.6 & 18.6 & 28 & 35.7 & 25.1 \\
\hline 3 months (t2) & 23 & 23.2 & 20.2 & 23 & 25.5 & 21.3 \\
\hline 6 months (t3) & 19 & 22.8 & 18.4 & 20 & 27.7 & 19.7 \\
\hline \multicolumn{7}{|c|}{$\begin{array}{l}\text { Treatment effect }(\mathrm{t} 0-\mathrm{t} 2) \text { after } 3 \text { months } p=0.529,(\mathrm{t} 0-\mathrm{t} 3) \text { after } 6 \text { months } p=0.186 \text {. } \\
\text { Effect size }(\mathrm{t} 0-\mathrm{t} 2) \text { after } 3 \text { months }-0.18,(\mathrm{t} 0-\mathrm{t} 3) \text { after } 6 \text { months }-0.35 \text {. }\end{array}$} \\
\hline \multicolumn{7}{|l|}{ Pain characteristics } \\
\hline End of radiotherapy (t1) & 27 & 32.1 & 25.5 & 28 & 42.5 & 29.3 \\
\hline 3 months (t2) & 23 & 26.6 & 25.0 & 23 & 25.5 & 21.3 \\
\hline 6 months (t3) & 19 & 31.6 & 18.2 & 20 & 27.8 & 27.8 \\
\hline \multicolumn{7}{|c|}{$\begin{array}{l}\text { Treatment effect ( } \mathrm{t} 0-\mathrm{t} 2) \text { after } 3 \text { months } p=0.300 \text {, ( } \mathrm{t} 0-\mathrm{t} 3) \text { after } 6 \text { months } p=0.324 \text {. } \\
\text { Effect size ( } 0 \text { - } 2 \text { ) after } 3 \text { months } 0.44,(\mathrm{t} 0-\mathrm{t} 3) \text { after } 6 \text { months } 0.41 \text {. }\end{array}$} \\
\hline \multicolumn{7}{|l|}{ Functional interference } \\
\hline End of radiotherapy $(\mathrm{t} 1)$ & 27 & 40.3 & 25.8 & 28 & 44.2 & 24.4 \\
\hline 3 months (t2) & 23 & 29.7 & 24.6 & 23 & 29.9 & 19.5 \\
\hline 6 months (t3) & 19 & 38.2 & 19.6 & 20 & 34.8 & 19.8 \\
\hline \multicolumn{7}{|c|}{$\begin{array}{l}\text { Treatment effect (t0-t2) after } 3 \text { months } p=0.851 \text {, (t0-t3) after } 6 \text { months } p=0.482 \text {. } \\
\text { Effect size (t0-t2) after } 3 \text { months } 0.03 \text {, (t0-t3) after } 6 \text { months } 0.27 \text {. }\end{array}$} \\
\hline \multicolumn{7}{|l|}{ Psychosocial aspects } \\
\hline End of radiotherapy (t1) & 27 & 54.9 & 24.0 & 28 & 53.2 & 23.6 \\
\hline 3 months (t2) & 23 & 50.2 & 26.3 & 23 & 52.9 & 21.9 \\
\hline 6 months (t3) & 19 & 44.7 & 27.6 & 20 & 46.4 & 21.0 \\
\hline
\end{tabular}

3DCRT: 3D conformal radiotherapy; SBRT: stereotactic body radiotherapy; SD: standard deviation.

single fraction was prescribed to that isodose line. OAR tolerance doses were per the RTOG 0631 trial (13). SBRT techniques included helical tomotherapy, step-and-shoot intensity-modulated radiotherapy, or volumetric-modulated arc therapy. Treatment was delivered by an Elekta Versa HD accelerator. Image guidance was performed in all patients by means of megavoltage CT and/or tomotherapy platforms.

For the 3DCRT arm, treatment was performed as irradiation of the involved vertebral body as well those immediately above and below, to a total dose of $30 \mathrm{~Gy}$ in 10 fractions, most commonly delivered with $3 / 4$ anteroposterior/posteroanterior beams. Position verification was carried out weekly before radiotherapy by kilovoltage cone-beam CT (kV-CBCT) and before each fraction by orthogonal portal images being compared with digitally reconstructed radiographs (DRR) from the planning CT.

Statistical analysis. On account of the explorative character of this study, it was not possible to estimate the total number of cases; however, with 30 patients per group, it was possible to detect a standardized effect (Cohen's d) of about 0.8 with $80 \%$ power and a significance level $(\alpha)$ of $5 \%$.

All statistical analyses were performed with SAS software v 9.4 (SAS Institute, Cary, NC, USA). All variables were analyzed descriptively by tabulation of the measures of the empirical distributions. According to the scale level of the variables, means, standard deviations, medians, as well as minimum and maximum (or absolute and relative frequencies) were reported. Additionally, for variables with longitudinal measurements, the time courses of individual patients are summarized by treatment groups. Descriptive $p$-values of the corresponding statistical tests comparing treatment groups were given. The Wilcoxon signed rank test was used to compare changes in group differences. Cohen's effect size (ES) was assessed for clinically relevant changes in questionnaire measures ( $<0.3$ low, 0.3-0.7 moderate, $>0.7$ strong differences).

\section{Results}

From November 2014 to March 2017, 60 patients were randomized. In total, five patients were excluded. Four patients in the SBRT arm had an insufficient distance between the tumor edge and spinal cord. One participant from the 3DCRT arm was excluded due to diagnosis of multiple myeloma. Thus, 55 patients met the inclusion/exclusion criteria and were enrolled (Figure 1). Baseline characteristics were mostly balanced between the two treatment arms (Table I). 
Table III. Effects of radiotherapy on fatigue in both groups (EORTC QLQ FA13).

\begin{tabular}{|c|c|c|c|c|c|c|}
\hline \multirow[b]{2}{*}{ Physical fatigue } & \multicolumn{3}{|c|}{ SBRT group } & \multicolumn{3}{|c|}{ 3DCRT group } \\
\hline & $\mathrm{n}$ & Mean & SD & $\mathrm{n}$ & Mean & SD \\
\hline End of radiotherapy $(\mathrm{t} 1)$ & 27 & 54.9 & 28.1 & 28 & 62.2 & 27.3 \\
\hline 3 months (t2) & 23 & 52.5 & 26.0 & 23 & 57.6 & 30.1 \\
\hline 6 months $(\mathrm{t} 3)$ & 19 & 50.9 & 24.8 & 20 & 59.6 & 26.3 \\
\hline \multicolumn{7}{|c|}{$\begin{array}{l}\text { Treatment effect }(\mathrm{t} 0 \text { - } \mathrm{t} 2) \text { after } 3 \text { months } p=0.708 \text {, (t0-t3) after } 6 \text { months } p=0.391 \text {. } \\
\text { Effect size (t0-t2) after } 3 \text { months }-0.03 \text {, (t0-t } 3) \text { after } 6 \text { months }-0.18 \text {. }\end{array}$} \\
\hline \multicolumn{7}{|l|}{ Emotional fatigue } \\
\hline End of radiotherapy $(\mathrm{t} 1)$ & 27 & 38.3 & 28.1 & 28 & 40.5 & 26.1 \\
\hline 3 months (t2) & 23 & 42.8 & 34.6 & 23 & 34.4 & 30.0 \\
\hline 6 months (t3) & 19 & 36.0 & 21.9 & 20 & 42.5 & 24.3 \\
\hline \multicolumn{7}{|c|}{$\begin{array}{l}\text { Treatment effect ( } \mathrm{t} 0 \text { - } \mathrm{t} 2) \text { after } 3 \text { months } p=0.596 \text {, ( } \mathrm{t} 0-\mathrm{t} 3) \text { after } 6 \text { months } p=0.260 \text {. } \\
\text { Effect size (t0-t2) after } 3 \text { months } 0.19,(\mathrm{t} 0-\mathrm{t} 3) \text { after } 6 \text { months }-0.41 \text {. }\end{array}$} \\
\hline \multicolumn{7}{|l|}{ Cognitive fatigue } \\
\hline End of radiotherapy $(\mathrm{t} 1)$ & 27 & 21.0 & 22.3 & 28 & 21.0 & 21.7 \\
\hline 3 months (t2) & 23 & 17.9 & 20.3 & 23 & 14.5 & 19.7 \\
\hline 6 months (t3) & 19 & 19.9 & 19.1 & 20 & 17.8 & 21.1 \\
\hline \multicolumn{7}{|c|}{$\begin{array}{l}\text { Treatment effect }(\mathrm{t} 0-\mathrm{t} 2) \text { after } 3 \text { months } p=0.723 \text {, }(\mathrm{t} 0-\mathrm{t} 3) \text { after } 6 \text { months } p=0.864 \text {. } \\
\text { Effect size ( } 0 \text { - } \mathrm{t} 2) \text { after } 3 \text { months }-0.05 \text {, (t0-t } 3) \text { after } 6 \text { months }-0.09 \text {. }\end{array}$} \\
\hline \multicolumn{7}{|l|}{ Interference with daily life } \\
\hline End of radiotherapy (t1) & 27 & 2.3 & 0.9 & 28 & 2.5 & 0.96 \\
\hline 3 months (t2) & 23 & 2.3 & 0.9 & 23 & 2.4 & 0.9 \\
\hline 6 months (t3) & 19 & 2.4 & 1.0 & 20 & 2.4 & 0.9 \\
\hline \multicolumn{7}{|c|}{$\begin{array}{l}\text { Treatment effect }(\mathrm{t} 0-\mathrm{t} 2) \text { after } 3 \text { months } p=0.720,(\mathrm{t} 0-\mathrm{t} 3) \text { after } 6 \text { months } p=0.646 \text {. } \\
\text { Effect size }(\mathrm{t} 0-\mathrm{t} 2) \text { after } 3 \text { months }-0.04,(\mathrm{t} 0-\mathrm{t} 3) \text { after } 6 \text { months }-0.04 \text {. }\end{array}$} \\
\hline \multicolumn{7}{|l|}{ Social sequlae } \\
\hline End of radiotherapy $(\mathrm{t} 1)$ & 27 & 1.3 & 0.67 & 28 & 1.2 & 0.4 \\
\hline 3 months (t2) & 23 & 1.4 & 0.7 & 23 & 1.2 & 0.4 \\
\hline 6 months $(\mathrm{t} 3)$ & 19 & 1.5 & 0.7 & 20 & 1.3 & 0.4 \\
\hline
\end{tabular}

3DCRT: 3D conformal radiotherapy; SBRT: stereotactic body radiotherapy; SD: standard deviation.

Although all surviving patients completed all assessments, not all patients survived by three and six months. Within the first 3 months, 4 patients $(14.8 \%)$ in the SBRT group had died, along with 5 patients $(17.9 \%)$ in the 3DCRT arm. Between 3-6 months, another 4 patients $(14.8 \%)$ died from tumor progression in the SBRT arm, along with a further 3 patients $(10.7 \%)$ in the 3DCRT cohort (Figure 1). Mortality did not differ between groups. The mean follow-up was 8.1 months $(95 \% \mathrm{CI}=6.87-8.97)$ for both arms.

QOL was evaluated by means of the EORTC QLQ-BM22 module. Therein, there were no significant differences between cohorts in terms of painful sites, pain characteristics, functional impairment, or psychosocial aspects at 3 and 6 months respectively ( $p>0.05$ for all) (Table II). Evaluation of fatigue using the EORTC QLQ FA13 module revealed no differences in any dimension between groups at either 3 or 6 months (Table III). Emotional distress as measured by the QSC-R10 module was also similar at three $(p=0.248)$ and six months $(p=0.603)$ (Table IV).

\section{Discussion}

Maintaining QOL in patients with advanced cancers is essential, as QOL impairment occurs by both disease as well as therapeutic interventions and their sequelae $(23,24)$. Radiotherapy-related symptoms can have a negative impact on both QOL and anxiety (25). This prespecified secondary evaluation of a prospective randomized trial is the first such study to investigate the impact of high-dose single-fraction SBRT on QOL as compared to 3DCRT in patients with painful spine metastases. 
Table IV. Effects of radiotherapy on emotional distress according to the FBK-R 10 questionnaire.

\begin{tabular}{|c|c|c|c|c|c|c|}
\hline \multirow[b]{2}{*}{ FBK R10 } & \multicolumn{3}{|c|}{ SBRT group } & \multicolumn{3}{|c|}{ 3DCRT group } \\
\hline & $\mathrm{n}$ & Mean & SD & $\mathrm{n}$ & Mean & SD \\
\hline End of radiotherapy (t1) & 27 & 17.0 & 9.7 & 28 & 19.0 & 9.1 \\
\hline 3 months (t2) & 23 & 17.0 & 9.3 & 23 & 16.5 & 9.4 \\
\hline 6 months (t3) & 19 & 15.3 & 9.9 & 20 & 17.4 & 9.6 \\
\hline
\end{tabular}

3DCRT: 3D conformal radiotherapy; SBRT: stereotactic body radiotherapy; SD: standard deviation.

As QOL becomes a more noteworthy component of cancer care in the future, these prospective data will be increasingly important to consider. Oncology is moving towards a valuebased system in which cost-effectiveness and QOL (both of which are closely linked) will progressively continue to be critically examined in efforts to provide evidence-based justification for a particular intervention, technology, and/or clinical approach. To this extent, it is essential to provide data regarding the "value" of a particular treatment paradigm. The implementation of new, sophisticated technologies not only brings advantages, but also entails risks of undesirable sequelae. It is hence important to demonstrate improved clinical outcomes while maintaining similar or improved QOL.

SBRT is a promising alternative to 3DCRT due to its ability to deliver high, ablative doses for durable local control while protecting adjacent organs-at-risk (OARs). Prospective investigations of SBRT for bone metastases have reported excellent tumor control, appropriate pain responses, and low toxicities $(12,13,26)$. However, there are serious adverse events associated with spinal SBRT, such as vertebral compression fractures (VCFs), that may require persistent and/or increased opiate usage and/or surgical intervention (27).

In light of these known risks, there were no QOL, fatigue, or emotional distress differences between arms in this study. There are several causes for this particular finding, including the particular types of questionnaires utilized and the relatively small sample sizes. It is also remarkable that the better pain response of the SBRT group (28) was not reflected in the QOL endpoints. Although also potentially related to issues regarding sample size and time points, there may also be major confounding issues that characterize a fundamental difference between a pain score and painassociated quality, functioning, and timing thereof. Dagneilie et al. found that, above all, fatigue has a major impact on overall QOL prior to RT (29), that finding can explain the lack of statistical differences in our results. Nevertheless, a highly relevant and comparable study by McDonald and colleagues showed a positive impact of pain control on QOL after palliative RT (30). In line with that data, Mendez et al. demonstrated a QOL benefit in responders to RT (31).

Taken together, QOL is a concept that is inherently dependent on time, as longer survival could manifest in differences between groups, but the heterogeneity in this population as well as its relatively lower survival herein may obscure any potential differences. As a result, it should also be mentioned that advancements in oncologic therapy for several types of metastatic cancer patients (e.g. immunotherapy and targeted agents) may prolong survival and could manifest in QOL differences. Hence, a salient point of this analysis is that the lack of statistical differences herein cannot definitively exclude subtle undetected differences.

Despite the prospective randomized nature of this study, there are several limitations, in addition to several explained above such as the small sample size, diversity in primary disease (and degree of control thereof), and lack of formal power calculations owing to the explorative nature. Moreover, because all patients had advanced cancer, this study did not account for progression or further therapies such as reirradiation or systemic therapies. These have major influences on QOL and should be evaluated in larger sample sizes in the future. Finally, as described elsewhere (16), it is crucial to mention that no study evaluating QOL or patient-reported outcomes can account for the innumerable factors that influence these variables, including prior or subsequent lines of therapy, baseline characteristics (32), social support, comorbidities, experience at the radiation facility, and nature of follow-up. As a result, further data are highly anticipated to validate the conclusions made herein.

\section{Conclusion}

This was a prespecified secondary analysis of a randomized trial, examining QOL, fatigue, and emotional distress following SBRT versus 3DCRT as part of palliative management of painful spinal metastases. Although these results demonstrate that SBRT does not cause worse QOL 
deteriorations compared to 3DCRT, larger randomized investigations are recommended to corroborate these findings.

\section{Conflicts of Interest}

The Authors declare that they have no competing interests. The sponsors of the study had no role in study design, data analysis, data interpretation and wording of the report. The corresponding Author (HR) had full access to the entire data of the study and had the final responsibility regarding the decision to submit for publication.

\section{References}

1 Wong DA, Fornasier VL and MacNab I: Spinal metastases: the obvious, the occult, and the impostors. Spine 15: 1-4, 1990.

2 Sze WM, Shelley M, Held I and Mason M: Palliation of metastatic bone pain: single fraction versus multifraction radiotherapy - a systematic review of the randomized trials. Cochrane Database Syst Rev 2: CD004721, 2004.

3 McQuay HJ, Collins SL, Carroll D and Moore RA: Radiotherapy for the palliation of painful bone metastases. Cochrane Database Syst Rev 2: Cd001793, 2000.

4 Sahgal A, Bilsky M, Chang EL, Ma L, Yamada Y, Rhines LD, Letourneau D, Foote M, Yu E, Larson DA and Fehlings MG: Stereotactic body radiotherapy for spinal metastases: current status, with a focus on its application in the postoperative patient. J Neurosurg Spine 14: 151-166, 2011.

5 Sahgal A, Ames C, Chou D, Ma L, Huang K, Xu W, Chin C, Weinberg V, Chuang C, Weinstein P and Larson DA: Stereotactic body radiotherapy is effective salvage therapy for patients with prior radiation of spinal metastases. Int J Radiat Oncol Biol Phys 74: 723-731, 2009.

6 Nguyen QN, Shiu AS, Rhines LD, Wang H, Allen PK, Wang XS and Chang EL: Management of spinal metastases from renal cell carcinoma using stereotactic body radiotherapy. Int J Radiat Oncol Biol Phys 76: 1185-1192, 2010.

7 Moussazadeh N, Lis E, Katsoulakis E, Kahn S, Svoboda M, DiStefano NM, McLaughlin L, Bilsky MH, Yamada Y and Laufer I: Five-year outcomes of high-dose single-fraction spinal stereotactic radiosurgery. Int J Radiat Oncol Biol Phys 93: 361367, 2015

8 Yamada Y, Bilsky MH, Lovelock DM, Venkatraman ES, Toner S, Johnson J, Zatcky J, Zelefsky MJ and Fuks Z: High-dose, single-fraction image-guided intensity-modulated radiotherapy for metastatic spinal lesions. Int J Radiat Oncol Biol Phys 71: 484-490, 2008.

9 Gerszten PC, Burton SA, Quinn AE, Agarwala SS and Kirkwood JM: Radiosurgery for the treatment of spinal melanoma metastases. Stereotact Funct Neurosurg 83: 213-221, 2005.

10 Guckenberger M, Mantel F, Gerszten PC, Flickinger JC, Sahgal A, Létourneau D, Grills IS, Jawad M, Fahim DK, Shin JH, Winey B, Sheehan J and Kersh R: Safety and efficacy of primary stereotactic body radiotherapy as primary treatment for vertebral metastases: a multy-institutional analysis. Radiat Oncol 9: 226, 2014.

11 Sahgal A, Roberge D, Schellenberg D, Purdie TG, Swaminath A, Pantarotto J, Filion E, Gabos Z, Butler J, Letourneau D, Masucci GL, Mulroy L, Bezjak A, Dawson LA and Parliament
M: The Canadian Association of Radiation Oncology scope of practice guidelines for lung, liver and spine stereotactic body radiotherapy. Clin Oncol (R Coll Radiol) 24: 629-639, 2012.

12 Kougioumtzopoulou A, Zygogianni A, Liakouli Z, Kypraiou E and Kouloulias V: The role of radiotherapy in bone metastases: A critical review of current literature. Eur J Cancer Care 26, 2017.

13 Ryu S, Pugh SL, Gerszten PC, Yin F-F, Timmerman RD, Hitchcock YJ, Movsas B, Kanner AA, Berk LB, Followill DS and Kachnic LA: RTOG 0631 phase 2/3 study of image guided stereotactic radiosurgery for localized (1-3) spine metastases: Phase 2 results. Pract Radiat Oncol 4: 76-81, 2014.

14 Schnipper LE, Davidson NE, Wollins DS, Blayney DW, Dicker AP, Ganz PA, Hoverman JR, Langdon R, Lyman GH, Meropol NJ, Mulvey T, Newcomer L, Peppercorn J, Polite B, Raghavan D, Rossi G, Saltz L, Schrag D, Smith TJ, Yu PP, Hudis CA, Vose JM and Schilsky RL: Updating the American Society of Clinical Oncology Value Framework: Revisions and Reflections in Response to Comments Received. J Clin Oncol 34: 2925-2934, 2016.

15 Verma V, Mishra MV and Mehta MP: A systematic review of the cost and cost-effectiveness studies of proton radiotherapy. Cancer 122: 1483-1501, 2016.

16 Verma V, Simone CB, 2nd and Mishra MV: Quality of life and patient-reported outcomes following proton radiation therapy: A systematic review. J Natl Cancer Inst 110, 2018.

17 Yates JW, Chalmer B and McKegney FP: Evaluation of patients with advanced cancer using the Karnofsky performance status. Cancer 45: 2220-2224, 1980.

18 Rief H, Katayama S, Bruckner T, Rieken S, Bostel T, Forster R, Schlampp I, Wolf R, Debus J and Sterzing F: High-dose single-fraction IMRT versus fractionated external beam radiotherapy for patients with spinal bone metastases: study protocol for a randomized controlled trial. Trials 16: 264, 2015.

19 Chow E, Nguyen J, Zhang L, Tseng LM, Hou MF, Fairchild A, Vassiliou V, Jesus-Garcia R, Alm El-Din MA, Kumar A, Forges F, Chie WC and Bottomley A: International field testing of the reliability and validity of the EORTC QLQ-BM22 module to assess health-related quality of life in patients with bone metastases. Cancer 118: 1457-1465, 2012.

20 Weis J, Arraras JI, Conroy T, Efficace F, Fleissner C, Gorog A, Hammerlid E, Holzner B, Jones L, Lanceley, A Singer S, Wirtz M, Flechtner H and Bottomley A: Development of an EORTC quality of life phase III module measuring cancerrelated fatigue (EORTC QLQ-FA13). Psychooncology 22: 1002-1007, 2013.

21 Book K, Marten-Mittag B, Henrich G, Dinkel A, Scheddel P, Sehlen S, Haimerl W, Schulte T, Britzelmeir I and Herschbach P: Distress screening in oncology-evaluation of the Questionnaire on Distress in Cancer Patients-short form (QSC-R10) in a German sample. Psychooncology 20: 287293, 2011.

22 Escalante CP: Treatment of cancer-related fatigue: an update. Support Care Cancer: official journal of the Multinational Association of Supportive Care in Cancer 11: 79-83, 2003.

23 Karunanithi G, Sagar RP, Joy A and Vedasoundaram P: Assessment of psychological distress and its Effect on quality of life and social functioning in cancer patients. Indian J Palliat Care 24: 72-77, 2018. 
24 Mystakidou K, Tsilika E, Parpa E, Gogou P, Panagiotou I, Vassiliou I and Gouliamos A: Relationship of general selfefficacy with anxiety, symptom severity and quality of life in cancer patients before and after radiotherapy treatment. Psychooncology 22: 1089-1095, 2013.

25 Gogou P, Tsilika E, Parpa E, Kouvaris I, Damigos D, Balafouta M, Maureas V and Mystakidou K: The impact of radiotherapy on symptoms, anxiety and QoL in patients with cancer. Anticancer Res 35: 1771-1775, 2015.

26 Pasqualetti F, Panichi M, Sainato A, Baldaccini D, Cocuzza P, Gonnelli A, Montrone S, Molinari A, Barbiero S, Bruschi A, Notini E, Ursino S, Mazzotti V, Morganti R, Coraggio G, Cantarella M, Erba PA and Paiar F: Image guided Stereotactic Body Radiotherapy in Metastatic Prostata Cancer. Anticancer Res 38: 3119-3122, 2018.

27 Sahgal A, Whyne CM, Ma L, Larson DA and Fehlings MG: Vertebral compression fracture after stereotactic body radiotherapy for spinal metastases. Lancet Oncol 14: e310-e320, 2013.

28 Sprave T, Verma V, Förster R, Schlampp I, Bruckner T, Bostel T, Welte SE, Tonndorf-Martini E, Nicolay NH, Debus J and Rief $\mathrm{H}$ : Randomized phase II trial evaluating pain response in patients with spinal metastases following stereotactic body radiotherapy versus three-dimensional conformal radiotherapy. Radiother Oncol, 2018. doi: 10.1016/j.radonc.2018.04.030. [Epub ahead of print]
29 Dagnelie PC, Pijls-Johannesma MC, Lambin P, Beijer S, De Ruysscher D and Kempen GI: Impact of fatigue on overall quality of life in lung and breast cancer patients selected for high-dose radiotherapy. Ann Oncol 18: 940-944, 2007.

30 McDonald R, Ding K, Brundage M, Meyer RM, Nabid A, Chabot P, Coulombe G, Ahmed S, Kuk J, Dar AR Mahmud A, Fairchild A, Wilson CF, Wu JSY, Dennis K, DeAngelis C, Wong RKS, Zhu L, Chan S and Chow E: Effect of radiotherapy on painful bone metastases: A secondary analysis of the NCIC Clinical Trials Group Symptom Control Trial SC.23. JAMA Oncol 3: 953-959, 2017.

31 Mendez LC, Raman S, Wan BA, da Silva JLP, Moraes FY, Lima K, Silva MF, Diz M, Chow E and Marta GN: Quality of life in responders after palliative radiation therapy for painful bone metastases using EORTC QLQ-C30 and EORTC QLQ-BM22: results of a Brazilian cohort. Ann Palliat Med 6: S65-70, 2017.

32 Nieder C and Kämpe TA: Contribution of patient-reported symptoms before palliative radiotherapy to development of multivariable prognostic models. Anticancer Res 38: 1705-1709, 2018.

Received May 31, 2018

Revised July 7, 2018

Accepted July 11, 2018 